\title{
Sinopse do gênero Brevoxathres Gilmour (Coleoptera, Cerambycidae)
}

\author{
Miguel A. Monné
}

${ }^{1}$ Museu Nacional, Universidade Federal do Rio de Janeiro. Quinta da Boa Vista, São Cristovão, 20940-040 Rio de Janeiro-RJ, Brasil. Bolsista do CNPq.

\begin{abstract}
Synopsis of the genus Brevoxathres Gilmour (Coleoptera, Cerambycidae). Brevoxathres is included in a group of five similar genera of Neotropical Acanthocinini. A key to identificate these genera is given. Sciadosurus Gilmour, 1962 is considered a new synonym of Brevoxathres. Two new species are described from Brazil: Brevoxathres seabrai sp. nov., from Espírito Santo and Rio de Janeiro and B. irrorata sp. nov. from Santa Catarina. A new combination, Brevoxathres albobrunnea (Gilmour, 1962), comb. nov., is proposed. A key to species is added.
\end{abstract}

KEYWORDS. Acanthocinini; Lamiinae; Neotropical; taxonomy.

RESUMO. Sinopse do gênero Brevoxathres Gilmour (Coleoptera, Cerambycidae). Brevoxathres inclui-se num grupo similar com cinco gêneros de Acanthocinini. Chave para identificação destes gêneros é oferecida. Sciadosurus Gilmour, 1962 é considerado novo sinônimo de Brevoxathres. Duas espécies novas são descritas do Brasil, Brevoxathres seabrai sp. nov. do Espírito Santo e Rio de Janeiro e B. irrorata sp. nov. de Santa Catarina. Uma nova combinação é proposta: Brevoxathres albobrunnea (Gilmour, 1962) comb. nov. Chave para espécies é adicionada.

PALAVRAS-CHAVE. Acanthocinini; Lamiinae; Neotropical; taxonomia.

Prosseguindo o estudo dos Acanthocinini neotropicais apresento a sinopse do gênero Brevoxathres Gilmour,1959, hoje composto por duas espécies, às quais acrescento mais duas espécies novas do Brasil e uma nova combinação, elevando o total para cinco. As abreviaturas das instituições são: MNRJ, Museu Nacional, Universidade Federal do Rio de Janeiro, Rio de Janeiro, MZSP, Museu de Zoologia, Universidade de São Paulo, São Paulo e UERJ, Universidade do Estado do Rio de Janeiro, Rio de Janeiro.

Brevoxathres Gilmour situa-se num grupo de gêneros que apresentam: élitros com setas eretas, sem cristas centro-basais e sem carenas laterais, tubérculos do protórax látero-centrais ou ligeiramente pós-medianos; pronoto sem elevações e com apenas uma fileira de pontos junto ao bordo posterior; mesosterno sem tubérculos e primeiro metatarsômero tão longo ou apenas mais curto que os dois seguintes em conjunto.

O grupo abrange os gêneros Proseriphus Monné, 2005, Pseudocriopsis Melzer, 1931, Alcidion Sturm, 1843 e Sciadosoma Melzer, 1934, que são diferenciados pelos caracteres mencionados na chave abaixo:

1. Meso-e metatíbias achatadas, densamente pilosas

Pseudocriopsis Melzer

Meso- e metatíbias cilíndricas, esparsamente pilosas ... 2

2(1). Superfície dorsal densamente revestida de escamas verdes, com brilho metálico Proseriphus Monné

Superfície dorsal sem escamas

3(2). Élitros sem carenas nítidas na metade distal

Brevoxathres Gilmour

Élitros com carena nitidamente demarcada, paralela e próxima da sutura nos $3 / 4$ ou na metade distal
4(3). Urotergito V truncado ou subemarginado na margem apical em ambos os sexos, os ângulos projetados em espinho longo e aguçado

Alcidion Sturm

Urotergito $\mathrm{V}$ arredondado na margem apical em ambos os sexos, sem espinhos aguçados

Sciadosoma Melzer

\section{Brevoxathres Gilmour, 1959}

Brevoxathres Gilmour, 1959: 33; Monné, 2005: 26 (catálogo).

Espécie tipo - Brevoxathres fasciata Gilmour, 1959 (monotipia e designação original).

Sciadosurus Gilmour, 1962: 258; Monné, 2005: 125 (catálogo), syn. nov.

Espécie tipo - Sciadosurus albobrunneus Gilmour, 1962 (monotipia e designação original).

A pormenorizada descrição original torna dispensável a repetição dos caracteres genéricos. Apenas acrescento, na chave, aqueles que permitem situar o gênero entre outros similares.

A comparação entre as espécies-tipo de Brevoxathres e Sciadosurus permitiu propor a sinonímia acima.

Chave para as espécies de Brevoxathres.

1. Ápices dos élitros arredondados ..................................... 2

Ápices dos élitros truncados ........................................... 3

2(1). Pubescência elitral cinzenta e castanho-escura, cabeça e protórax recobertos por pilosidade acinzentada. Brasil (Amazonas, Pará), Peru (Junin, Madre de Dios), Bolívia (SantaCruz). (Fig. 4) B. albobrunnea (Gilmour) comb. nov. 
Pubescência elitral branca e preta; cabeça e pronoto predominantemente revestidos de pilosidade branca, com brilho sedoso. Brasil (Santa Catarina) (Fig. 6) B. irrorata sp. nov.

3(1). Antenas, tíbias e abdomen com longos pêlos eretos; pubescência do protórax e élitros predominantemente amarelo-dourada. Brasil (Espírito Santo, Rio de Janeiro). (Fig. 5) B. seabrai sp. nov. Antenas, tíbias e abdomen sem pêlos longos; pubescência elitral predominantemente esbranquiçada

4(3). Tubérculos laterais do protórax rombos, sem projeção espiniforme no ápice; élitros densamente pontuados em toda a superfície. Brasil (Santa Catarina). (Fig. 1) B. fasciata Gilmour

Tubérculos laterais do protórax rombos, com projeção apical espiniforme dirigida para trás; élitros com pontos moderadamente esparsos e restritos à metade anterior. Brasil (Bahia a São Paulo), Bolívia. (Figs 2, 3) B. $x$-littera (Melzer)

\section{Brevoxathres fasciata Gilmour, 1959}

(Fig. 1)

Brevoxathres fasciata Gilmour, 1959: 35, pr. 1, fig. 4; Monné, 2005: 27 (catálogo).

Descrita com base num macho proveniente do Brasil, Santa Catarina, Corupá (Gilmour 1959). Os últimos urotergito e urosternito da fêmea são triangularmente entalhados na margem apical e os ângulos não apresentam projeções espiniformes.

Material examinado. BRASIL. Santa Catarina: Corupá, fêmea, X.1938; dois machos, fêmea, XI.1953; fêmea XI.1954,A. Maller col. Todos no MNRJ.

Brevoxathres $x$-littera (Melzer, 1932) (Figs. 2, 3 )

Probatius x-littera Melzer, 1932: 430, pr. 6, fig. 5.

Brevoxathres x-littera; Gilmour, 1965: 597 (catálogo); Monné, 2005: 27 (catálogo).

Examinei o holótipo macho, proveniente do Brasil, Espírito Santo, Fazenda Jerusalem (MZSP). Acrescento a descrição dos urotergito e urosternito $\mathrm{V}$ : macho com o último urotergito triangularmente emarginado; último urosternito semicircularmente entalhado. Fêmea: ovipositor projetado cerca de $2 \mathrm{~mm}$ além das extremidades dos élitros; último urotergito semicircularmente entalhado, ângulos espinhosos; último urosternito truncado, densamente piloso na extremidade distal.

Material examinado. BRASIL. Bahia: Itamarajú, 9 machos, 7 fêmeas, X.1985, O. Roppa \& J. Becker col.; Encruzilhada, (Motel da
Divisa, Estrada Rio-Bahia km 965), 960 m; 2 machos, fêmea, XI.1972, fêmea, XII.1972, 2 fêmeas, XI.1974, macho, fêmea, XII.1974, C. A. C. Seabra \& O. Roppa col. Minas Gerais: Pedra Azul, fêmea, XI.1972, C. A. C. Seabra \& F. M. Oliveira col. Espírito Santo: Linhares, fêmea, X.1967, F. M. Oliveira col.; macho, XII.1971, B. Silva col. (Parque Sooretama), 5 machos, 4 fêmeas, XII.1967, F. M. Oliveira \& B. Silva col.; 2 fêmeas, X.1968, F. M. Oliviera col. São Paulo: Barueri, fêmea, X.1958, K. Lenko. col. Mun. Mogi das Cruzes, (Rio Tiete), macho, 7.I.1989, M. A. Monné col. BOLIVIA. Santa Cruz: Santa Cruz, 500 m, macho, X.1960, R. Zischka col. Todos no MNRJ.

Os exemplares provenientes do Estado de São Paulo (Fig. 3) apresentam a pubescência elitral predominantemente esbranquiçada, sem ou com escassas máculas castanho-claras.

\section{Brevoxathres albobrunnea (Gilmour, 1962) comb. nov.} (Fig. 4)

Sciadosurus albobrunneus Gilmour, 1962: 259, pr. 1, fig. 4; Monné, 2005: 125 (catálogo).

Descrita com base numa fêmea proveniente de Peru, Junin, Satipo (Gilmour 1962). Os machos apresentam os urotergito e urosternito V semicircularmente emarginados.

Material examinado. BRASIL. Amazonas: Massanari (Rio Maués), fêmea, sem data, Hahnel col. Pará: Óbidos, macho, 2 fêmeas, I.1956, F. M. Oliveira col. PERU. Junin: Satipo, macho, fêmea, X.1940, sem coletor, fêmea, XI.1941, sem colector. Madre de Dios: Avispas, 3 machos, fêmea, IX.1962, L. Peña col. BOLÍVIA. Santa Cruz: Chapare, macho, 12.IX.1943, fêmea, 30.X.1945, fêmea, 30.XI.1945, fêmea, 4.XI.1947, Zellibor leg. Todos no MNRJ.

\section{Brevoxathres seabrai sp. nov.} (Fig. 5 )

Macho. Tegumento castanho-avermelhado; as metades anteriores dos antenômeros III-XI castanho-amarelados e revestidos com pubescência esbranquiçada. Pubescência predominantemente cinzento-acastanhada. Pronoto com duas faixas longitudinais de pubescência amarelo-dourada. Escutelo com pubescência castanho-escura. Élitros com manchas castanho-escuras, a anterior, pós-escutelar, triangular, e a mediana transversa, mais alargada para as margens. Pubescência amarelo-dourada disposta em manchas de contorno irregular em toda a superfície elitral, mais densa e nítida numa faixa transversa no fim do terço anterior.

Antenas alcançam as extremidades dos élitros aproximadamente no ápice do antenômero VI; antenômeros III-VII com longos pêlos eretos em toda a superfície. Tubérculos laterais do protórax apenas pós-medianos, os ápices aguçados e voltados para trás. Élitros com abundantes e longos pêlos eretos; ápices obliquamente truncados, ângulos não espinhosos; pontos pilíferos igualmente distribuídos em toda a superfície; pontos não piliferos escassos e restritos ao quarto basal. Tíbias com longos pêlos eretos. Primeiro metatarsômero apenas mais curto que os dois seguintes em conjunto. Metasterno e abdômen com longos pêlos eretos, esparsos. Últimos urotergito e urosternito subemarginados.

Fêmea. Antenas atingem as extremidades dos élitros 

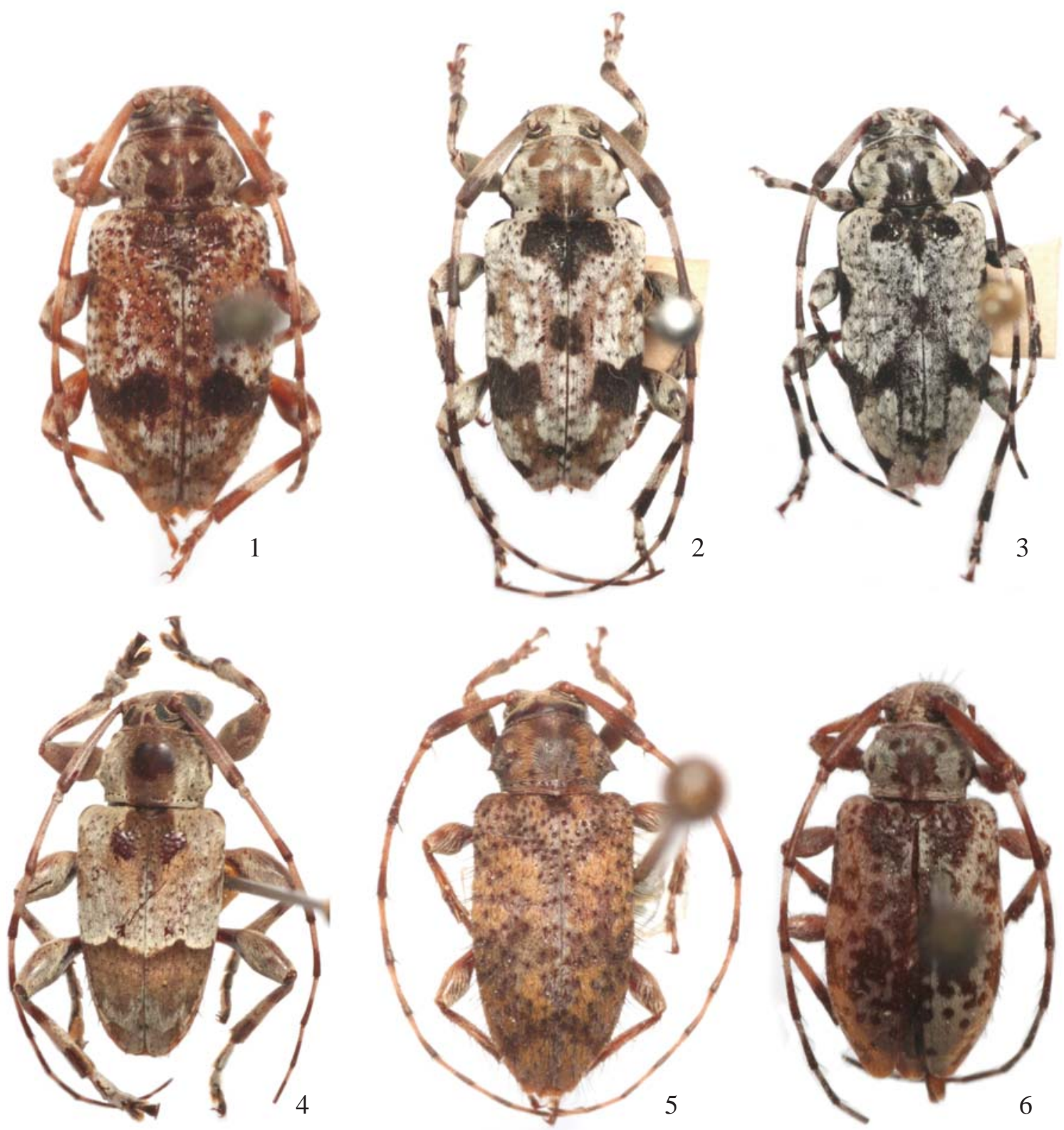

Figs. 1-6. 1, Brevoxathres fasciata Gilmour, 1959, fêmea, Corupá, Santa Catarina, comprimento, 8,0 mm; 2, B. x-littera (Melzer, 1932), macho, Itamarajú, Bahia, comprimento, 11,2 mm; 3, B. x-littera (Melzer, 1932), fêmea, Rio Tieté, Mun. Mogi das Cruzes, São Paulo, comprimento 9,2 mm; 4, B. albobrunnea (Gilmour, 1962), macho, Avispas, Madre de Dios, Peru, comprimento 12,0 mm; 5, B. seabrai sp. nov. , parátipo fêmea, Corcovado, Rio de Janeiro, comprimento $7,2 \mathrm{~mm}$;, B. irrorata sp. nov. parátipo fêmea, Corupá, Santa Catarina, comprimento, 6,0 mm.

aproximadamente no ápice do antenômero VII. Urotergito V arredondado, urosternito $\mathrm{V}$ truncado. Ovipositor apenas ultrapassa a ponta dos élitros.

Dimensões, em mm, macho/fêmea. Comprimento total, 4,55,7/6,2-7,5; comprimento do protórax, 1,0-1,2/1,3-1,5; maior largura do protórax, 1,5-2,0/2,1-2,5; comprimento do élitro, 3,24,1/4,5-5,4; largura umeral, 1,8-2,4/2,5-3,1.

Material-tipo. Holótipo macho, BRASIL. Rio de Janeiro: Rio de Janeiro (Corcovado), 10.X.1958, M. Alvarenga \& C. A. C. Seabra col. (MNRJ). Parátipos: BRASIL, Espírito Santo: Linhares, fêmea, X.1971, S. A. Fragoso col.; fêmea, IX.1972, B. Silva col. Rio de Janeiro: Rio de Janeiro (Corcovado), fêmea, 6.X.1952, fêmea, 16.X.1954, D. Zajciw col., fêmea, 18.X.1957, fêmea, 17.XI.1958, fêmea, 30.IX.1959, fêmea, X.1962, macho, 27.X.1966, fêmea, 8.XI.1966, macho, 2.X.1967, C A. C. Seabra \& M. Alvarenga col.; fêmea, 2.X.1967, S. A. Fragoso col.; macho, 13.XII.1967, C. A. C. Seabra col.; macho, fêmea, 5.X.1968, fêmea, 24.X.1968, S. A. Fragoso col.; fêmea, 30.IX.1971, fêmea, 4. X. 1971, C. A. C. Seabra col. Todos no MNRJ.

Comentários. Em alguns exemplares as manchas castanhoescuras dos élitros estão entremeadas com pubescência amarelada. Separa-se das outras espécies pelos caracteres arrolados na chave.

O epíteto homenageia o saudoso Dr. Carlos Alberto Campos Seabra, profundo conhecedor da fauna de Cerambycidae. 


\section{Brevoxathres irrorata sp. nov.}

(Fig. 6 )

Fêmea. Tegumento preto a castanho; ápice dos antenômeros III-XI, fêmures e terço apical das tíbias, pretos. Cabeça, metade anterior do escapo e dos antenômeros III-XI revestidos com densa pubescência branca. Protórax recoberto por pilosidade esbranquiçada, exceto mancha mediana longitudinal que não alcança o bordo anterior (e engloba estreita linha branca), ápices dos tubérculos laterais e pequenas máculas arredondadas, coalescentes ou não com a mancha mediana, castanho-escuros. Escutelo preto. Élitros com densa pubescência esbranquiçada e abundantes máculas arredondadas pretas, parcialmente fundidas em mancha pósescutelar e mediana transversa. Fêmures, metade anterior das tíbias e face ventral com densa pubescência branca.

Antenas alcançam os ápices dos élitros aproximadamente na extremidade distal do antenômero VI. Tubérculos laterais do protórax apenas pós-medianos, os ápices aguçados e voltados para trás. Élitros com os ápices arredondados; pontos pilíferos uniformemente distribuídos em toda a superfície, pontos não pilíferos pequenos e escassos, restritos ao terço basal. Primeiro metatarsômero tão longo quanto os dois seguintes em conjunto. Urotergito $\mathrm{V}$ arredondado, urosternito $\mathrm{V}$ truncado.

Dimensões, em mm, fêmea. Comprimento total, 5,6-6,4; comprimento do protórax, 1,0-1,3; maior largura do protórax, 1,8-2,0; comprimento do élitro, 4,2-4,6; largura umeral, 2,2-2,5.

Holótipo fêmea, BRASIL, Santa Catarina: Corupá, XI.1966, A. Maller col. (MNRJ). Parátipos, mesma procedência e coletor, fêmea, X.1938; fêmea, X.1964. (MNRJ).

Comentários. Brevoxathres irrorata difere de suas congêneres pelos caracteres indicados na chave.

Agradecimentos. À Dra. Marcela Laura Monné (MNRJ) pela revisão do manuscrito e ao Dr. José Ricardo Miras Mermudes (UERJ) pela execução das fotografias.

\section{REFERÊNCIAS}

Gilmour, E. F. 1959. On the Neotropical Acanthocinini VI (Coleoptera, Cerambycidae, Lamiinae). Some new genera and species II. Anales de la Sociedad de Biologia 1959: 23-38.

Gilmour, E. F. 1962. On the Neotropical Acanthocinini (Coleoptera, Cerambycidae, Lamiinae). Some new genera and generic revision. Beiträge zur Neotropischen Fauna 2: 249-293.

Gilmour, E. F. 1965. Catalogue des Lamiaires du Monde (Col., Cerambycidae). 8 Lief. Museum G. Frey, Tutzing bei München, p. $559-655$

Melzer, J. 1932. Novos gêneros e novas espécies de cerambycideos do Brasil. Revista de Entomologia 2: 420-434.

Monné, M. A. 2005. Catalogue of the Cerambycidae (Coleoptera) of the Neotropical Region. Part II. Subfamily Lamiinae. Zootaxa 1023: $1-759$. 